\title{
Fluid Mechanical Aspects of the Gas-Lift Technique
}

\section{S. Guet and G. Ooms}

J.M. Burgerscentrum, Laboratory for Aero and Hydrodynamics, Delft University of Technology, 2628 CA Delft, The Netherlands; email: S.C.L.Guet@wbmt.tudelft.nl, G.Ooms@wbmt.tudelft.nl

Annu. Rev. Fluid Mech.

2006. 38:225-49

The Annual Review of Fluid Mechanics is online at fluid.annualreviews.org

doi: 10.1146/annurev.fluid. 38.061505 .093942

Copyright (c) 2006 by Annual Reviews. All rights reserved

0066-4189/06/0115$0225 \$ 20.00$

\section{Key Words}

bubbly flow, bubble size, lift force, stability

\begin{abstract}
The gas-lift technique comprises the injection of gas bubbles in vertical oil wells to increase production. It is based on a reduction of the tubing gravitational pressure gradient. Several fluid-flow phenomena influencing such vertical gas-liquid flows are discussed. These effects include the radial distribution of void fraction and of gas and liquid velocity, flow regime changes, and system stability problems. Associated consequences for gas-lift performance and related optimization approaches are also discussed.
\end{abstract}




\section{INTRODUCTION}

Two-phase gas-liquid flow problems are of interest to both fundamental research and industrial applications. They are encountered in a large variety of practical situations, such as bubble columns, stirring vessels, cavitating flows, or transportation lines. The different type of problems found in these various two-phase flow applications suggest two-phase flow problems to be seen as "a family of topics, rather than a single topic" (Batchelor 1989). A topic of particular relevance for large-scale industrial applications is a vertical upward bubbly flow in a pipe. This situation can, for instance, be found in airlift reactors for enhancing mixing, or for providing oxygen to microorganisms. It is also encountered in mining technologies and wastewater treatment.

For underground oil recovery the gas-lift technique is often used to enhance production (Figure 1). It is employed when, after years of production, a well down-hole pressure slowly decreases toward a situation of zero oil production. By using gas injection in the well tubing, the gravitational pressure drop in the well is reduced, resulting in a reduced pressure at the tube entrance (called bottom hole pressure, or BHP). In the case of an oil well, the reservoir pressure and the top-level pressure (called tubing head) are fixed on the scale of a day, i.e., the total pressure drop $\Delta P=\Delta P_{\text {tube }}+\Delta P_{\text {res }}$ is constant. The consequence of a lower pressure drop in the vertical pipe is an increased pressure drop through the reservoir $\Delta P_{\text {res }}$, resulting in an increased net oil

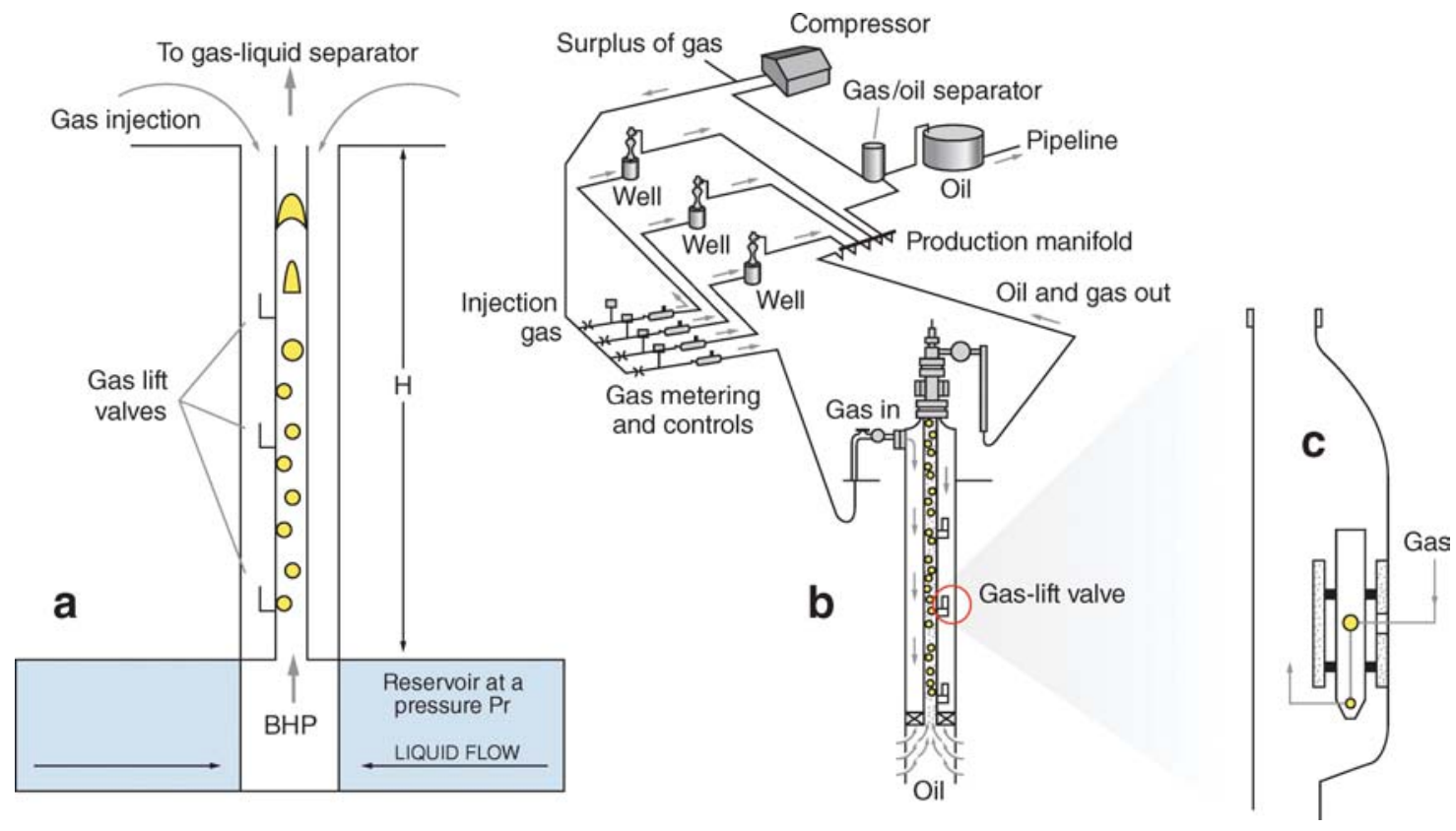

Figure 1

(a) Schematic view of a gas-lift installation. (b) Gas-lift installation, as implemented in practice. Details about the gas-injection geometry (side-pocket mandrel) are shown in $(c)$. 
flow rate (Figure 1a). Various types of gas-lift installations exist. Among them, one can distinguish continuous gas lift (which uses a stationary gas-injection input), dual gas-lifted wells (where the gas input is shared by two wells), or intermittent gas lift. In this review, we focus on continuous gas lift.

In Figure $\mathbf{1} \boldsymbol{b}$ a view of a gas-lift installation as implemented in practice is depicted. When a promising underground hydrocarbon reservoir is discovered, wells are drilled into the reservoir. After drilling, the walls of the well are cemented. This outside cement layer is called the casing. Inside the casing a pipeline (called the tubing) is placed for the production of oil (and gas). At the bottom of the tubing a seal (called the packer) is installed between the casing and the tubing. The space between the tubing and the casing is called the annulus. Perforations are shot into the casing below the packer to let the oil (and gas) flow from the reservoir into the tubing. The gas is put into the annulus from the top via a choke, and then injected from the annulus into the well tubing via a number of large nozzle injectors called gas-lift valves. Each valve is mounted on the tubing at a specific location, called side-pocket mandrel (Figure 1c). After the starting period only the deepest valve is injecting the gas because in principle it is the most efficient in reducing the gravitational pressure gradient.

At conditions where the gas-lift technique is applied, the pipe flow is turbulent: $R e_{s l}=\frac{U_{s l} D_{p}}{v_{l}} \approx 10000$, in which $U_{s l}$ is the liquid superficial velocity (the ratio of liquid volumetric flow rate to tube section), $D_{p}$ the pipe diameter, and $v_{l}$ the liquid viscosity. However, the turbulent intensity is not large enough to guarantee bubble breakup. These flow conditions and the use of a large nozzle injector result in a gravity-driven bubbly flow with relatively large bubbles.

The gas-lift technique efficiency has long been known to be influenced by a large number of flow parameters (Bertuzzi et al. 1953, Pennington 1927, Poetmann \& Carpenter 1952, Ros 1961). Selecting the appropriate flow conditions for applying the gas-lift technique at optimum efficiency, such as the gas input, the injector geometry, or the pipe diameter, is therefore a challenging issue.

Gas-lift performance prediction approaches are briefly reviewed. First, the models used for pressure gradient predictions in the reservoir and in the gas-liquid flow part of gas-lifted wells are explained. Thereafter, based on recent numerical and experimental results, an overview of the relevant fluid mechanical effects for gas-lift performance is given. These effects are essentially connected to the magnitude of the frictional pressure, the bubble relative motion, the void fraction radial profiles, the flow pattern, and the system stability. Optimization considerations in relation with these aspects are also discussed.

\section{GAS-LIFT SYSTEMS: PERFORMANCE AND PREDICTIONS}

The pressure drop in the pipe and in the reservoir determines the flow rate observed in a gas-lifted well. Those coupled parts of the well are commonly modeled using the inflow performance relationship (IPR) and the tubing performance curve (TPC) for predicting the flow-rate conditions in the reservoir and in the two-phase flow pipe, respectively. 


\subsection{Reservoir and Tubing Pressure}

2.1.1. Reservoir pressure. The IPR predicts the mean liquid flow rate associated with a given pressure drop in the reservoir. Using a relation derived from Darcy's law for the radial inflow through the reservoir, it is expressed by:

$$
Q_{l}=P_{I} \Delta P_{r e s},
$$

where $Q_{l}$ is the liquid volumetric flow rate, $\Delta P_{\text {res }}=P_{\text {res }}-B H P$ is the pressure drop from the far field reservoir to the tube entrance, and $P_{I}$ is the productivity index (PI). It characterizes an equivalent mean reservoir permeability.

2.1.2. Tubing pressure. The TPC relates the liquid flow rate to the pressure drop in the production tubing for a given ratio of gas-to-liquid input, $\beta=\frac{U_{s g}}{U_{s l}}$. The pressure gradient is considered the sum of the contributions due to gravity, friction, and acceleration, $\left[\frac{\partial P}{\partial z}\right]=\left[\frac{\partial P}{\partial z}\right]_{g}+\left[\frac{\partial P}{\partial z}\right]_{f}+\left[\frac{\partial P}{\partial z}\right]_{a}$.

The gravitational part is given by $\left[\frac{\partial P}{\partial z}\right]_{g}=\left\langle\rho_{m}\right\rangle g$, where $\left\langle\rho_{m}\right\rangle$ is the sectional average mixture density, given by the average void fraction $\langle\epsilon\rangle$ :

$$
\left\langle\rho_{m}\right\rangle=\langle\epsilon\rangle \rho_{g}+(1-\langle\epsilon\rangle) \rho_{l},
$$

where $\rho_{g}$ and $\rho_{l}$ are the density of the gas and of the liquid, respectively.

The frictional pressure gradient is generally estimated on the basis of available single-phase flow correlations of the form of $\left[\frac{\partial P}{\partial z}\right]_{f}=\frac{f_{m}}{2 D_{p}}\left\langle\rho_{m}\right\rangle U_{m}^{2}$, in which $f_{m}$ is a friction factor and $U_{m}=U_{s g}+U_{s l}$ is the mixture velocity. The contribution of acceleration can generally be neglected.

Examples of a TPC and an IPR curve are shown in Figure 2. Each curve corresponds to a given ratio of gas-to-liquid input $\beta$. At a fixed $\beta$-value the mean void fraction increases with increased liquid flow rate, therefore the gravitational pressure is reduced. However, the magnitude of the frictional pressure increases with

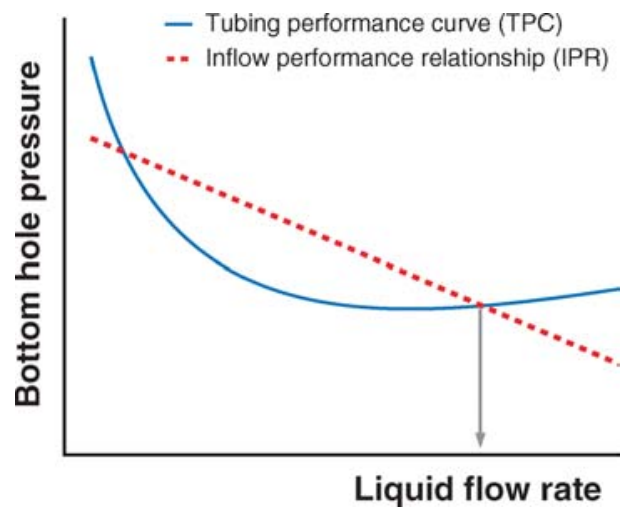

Figure 2

Gas-lift operating point determination, using the IPR and TPC curves. A TPC curve corresponds to a constant ratio of gas-to-liquid input. 
increased liquid flow rate; therefore the slope of the TPC curve changes with the liquid flow-rate conditions (Figure 2).

\subsection{Instability Generated by Gas-Lift Installation Systems}

Unstable operational conditions may occur in a continuous gas lift well because the characteristics of the system components of a gas-lift installation are such that small perturbations can lead to huge oscillations in the production flow. System components that are important for the generation of gas-lift instability are the gas-lift valve, the choke, the volume of the annulus, and the height of the tubing. The mechanism by which the gas-lift instability is generated is the following: If the BHP is slightly decreased, the tubing pressure decreases and hence the pressure drop through the gas-lift valve increases, resulting in an increased gas input. This causes a further reduction of the BHP and an additional increase of the oil flow rate. During this period, due to the reduced pressure a substantial amount of additional gas is blown into the tubing. This effect will only stop when the pressure in the annulus decreases due to the increase in gas flow rate via the gas-lift valve into the tubing. This decrease in annulus pressure is so strong that the gas flow rate through the gas-lift valve can become smaller than the original steady-state value and can eventually stop for a short period. The tubing pressure will rise again and the hydrocarbon production rate will decrease substantially. This effect will only stop when new gas is injected into the annulus via the choke (which causes a rise in the annulus pressure). If the system components are not tuned properly, this cycle will repeat itself and can become even stronger. Oscillations in tubing, in annulus pressure, and in the production rate are therefore observed at the surface (it is also called heading/casing instability). Figure 3 illustrates such production records for a well at Prudhoe Bay in Alaska in which such pressure cycles are observed (Hu \& Golan 2004).

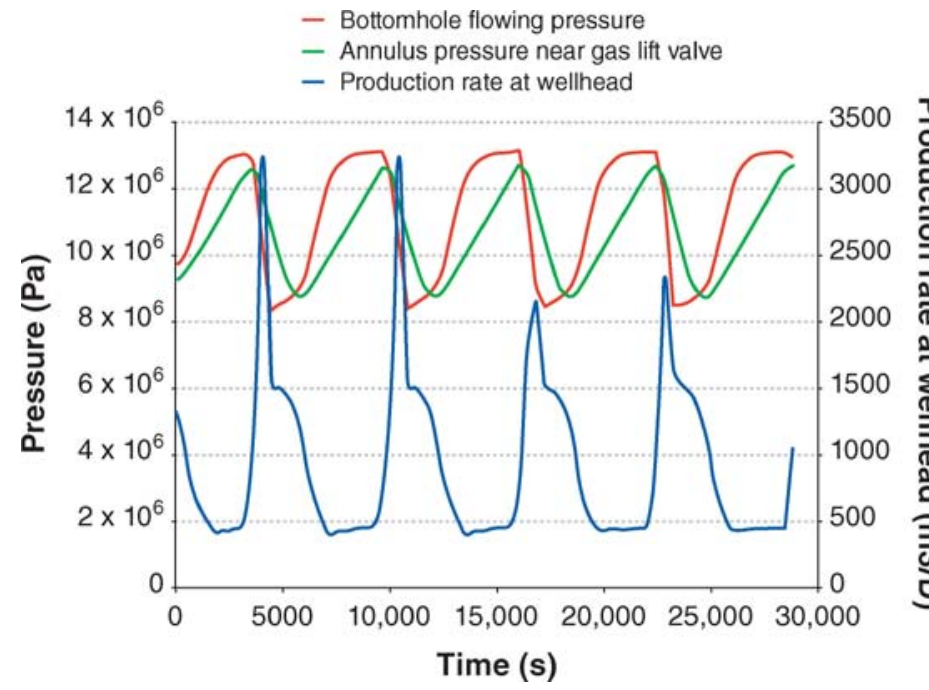

Figure 3

Typical coupled fluctuations between the gas pressure and the liquid flow rate during heading instability in a gas-lifted well (Hu \& Golan 2004). 
Perturbations of the bottom pressure are necessary to generate these instabilities. An important type of perturbation is the change in void fraction due to the occurrence of hydrodynamic instabilities generated by void fraction waves or by the nonstationary character of certain flow regimes. For instance, the pressure variations during slug flow in vertical pipes present such properties (Tutu 1982, 1984; see also Lin \& Hanratty 1989 for horizontal slug flow). In the present review we focus on the fluid mechanical aspects of stable continuous gas-lift operating conditions. These operating conditions are similar to flow conditions encountered in laboratory experiments because no global system instabilities are observed.

\subsection{Flow-Rate Predictions}

By combining the IPR and the TPCs, a well operating point can be determined. The two intersection points between the IPR and TPC curves give the potential operating conditions. However, the lower production rate point corresponds to an unstable equilibrium: If the liquid flow rate is reduced slightly, the BHP must be larger than the value that the reservoir can provide (it is, therefore, not a realistic situation and the well will stop flowing). If the liquid flow rate is perturbed positively, a lower BHP than the one provided by the reservoir is needed. Because the reservoir can provide this pressure, the liquid flow rate in the tubing is then driven toward larger values, corresponding to the second intersection point. The point used for stable gas-lift operation previsions is therefore the right-hand intersection point between the TPC and IPR curves in Figure 2. It corresponds to a positive slope of the TPC curve, where friction helps stabilize the flow.

Although the frictional pressure drop is important for stable gas-lift operations, the low to moderate liquid flow conditions corresponding to gas-lift applications imply that $\left|\left[\frac{\partial P}{\partial z}\right]_{f}\right|$ represents less than $10 \%$ of the overall pressure gradient. The gravitational pressure gradient is therefore the most important one for gas-lift performance predictions. More specifically, the value of the area average void fraction $\langle\epsilon\rangle$ associated with given global flow conditions is a key point because it can have a significant influence on $\left\langle\rho_{m}\right\rangle$.

In gas-liquid flow conditions encountered during gas-lift operations, the residence time of the gas bubbles and of the liquid in the pipe flow are different, due to the nonzero relative velocity between the gas and the liquid and the radial heterogeneities of phase velocities and of phase fractions. The existing flow pattern also has an important impact on the residence times. These effects result in an important influence of certain parameters, such as bubble size, the presence of surfactants, or the flow-input conditions.

\section{RELEVANT LOCAL FLOW PHENOMENA}

\subsection{Bubble Relative Velocity}

The relative velocity between a gas bubble and the surrounding liquid is essentially the result of a competition between the gravity, drag, and added mass forces. Experimental 


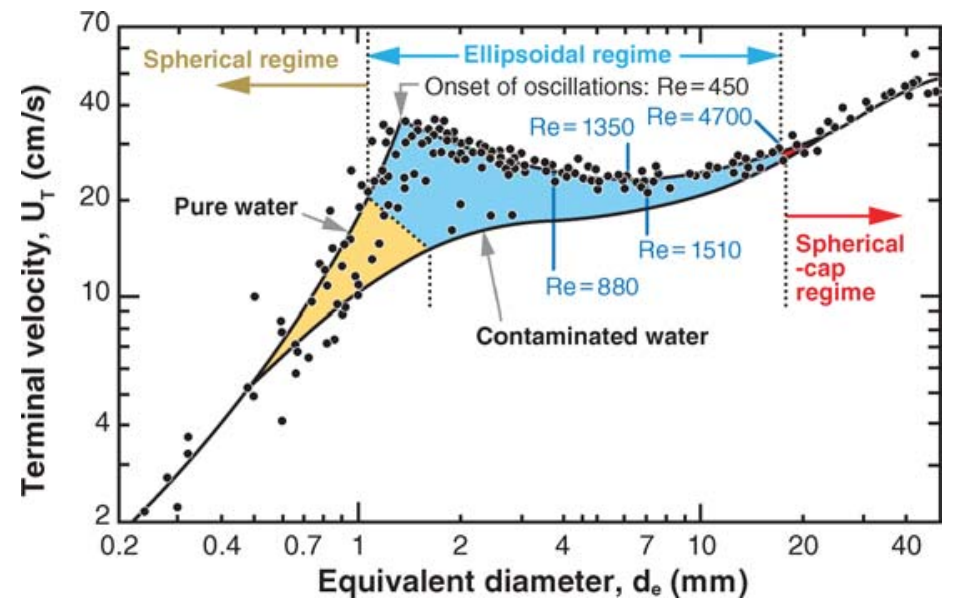

results on the rise velocity of single bubbles in an infinite medium of water have been collected from various experimental studies in Clift et al. (1978) (Figure 4). Because gravity is the dominant force for large bubbles, the bubble terminal velocity increases with the equivalent diameter of the bubble. The terminal velocities in clean and contaminated liquids are different for a given equivalent bubble diameter. This is due to the changes in bubble shape with the contamination level, which in turn affects the equivalent drag-force coefficient (Tomiyama et al. 2002a).

In multiple bubble flow conditions, i.e., bubbly flow with nonzero gas fraction, the mean relative velocity between the gas bubbles and the liquid as measured with local measurement techniques is lower than the value of the terminal velocity of a single bubble in an infinite medium. This void fraction effect on the bubble relative velocity $U_{r}=U_{g}-U_{l}$ can be taken into account by using a hindering function $b(\epsilon)$ (Garnier et al. 2002, Richardson \& Zaki 1954, Rivière \& Cartellier 1999, Zenit et al. 2001):

$$
U_{r}=U_{t} h(\epsilon)
$$

in which $U_{t}$ is the terminal velocity of a single bubble in an infinite medium (as described by Figure 4), and $0<b(\epsilon)<1$. Independently from the correlation used, the main feature of the hindering function $b(\epsilon)$ is to predict a decreased bubble relative velocity with increased void fraction, i.e., $h(\epsilon)$ is a decreasing function of $\epsilon$. This effect is attributed to the hydrodynamic interactions and to the reference liquid velocity seen by the bubbles, or interstitial velocity, which is different from the time average liquid velocity (Kowe et al. 1988).

Recently, Eames et al. (2004) studied the velocity through and around a group of bodies and extended this interstitial velocity concept developed by Kowe et al. (1988). It was shown that, for low values of the void fraction $\epsilon$, the hindering function could be expressed as $h(\epsilon)=\left[1-\left(1+C_{a m}\right) \epsilon\right]$, where $C_{a m}$ is the added mass force coefficient $\left(C_{a m} \approx \frac{1}{2}\right.$ for a nearly spherical bubble). As noted by the authors, this expression compares very well with the value obtained by van Wijngaarden (1993),
Figure 4

Terminal velocity of a single bubble in water as a function of the bubble spherical equivalent diameter (from Clift et al. 1978, p. 172). 


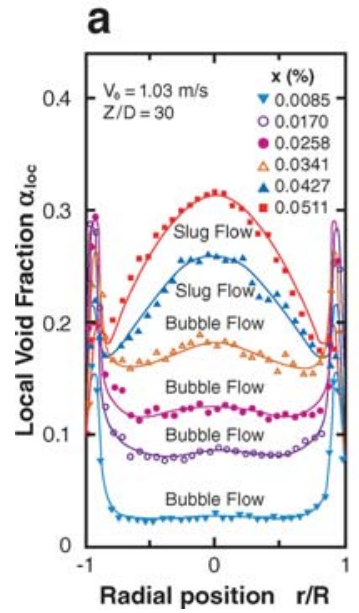

who analyzed binary bubble interactions and obtained $h(\epsilon)=1-C \epsilon$, where the constant $C$ was ranging from 1.43 to 1.56 depending on the truncation used in the calculations.

Another commonly used formulation for the hindering function follows from Richardson \& Zaki (1954): $h(\epsilon)=(1-\epsilon)^{n}$. The exponent $n$ is often obtained from experiments and depends on the bubble size and shape (van Wijngaarden 1991). More recently, the experiments of Garnier et al. (2002) showed that the decreased bubble relative velocity scales with the bubble interdistance for a large range of void fraction conditions $(0<\epsilon<0.25)$. The associated hindering function is $h(\epsilon)=1-\epsilon^{\frac{1}{3}}$. This formulation correctly describes the bubble relative velocity of small bubbles (Garnier et al. 2002, Guet et al. 2004). However, provided the exponent $n$ is adjusted to the experimental results, the formulation of Richardson \& Zaki (1954) is flexible enough for describing a large range of bubble-size and input-flow conditions (Apazidis 1985, Zenit et al. 2001).

\subsection{Void Fraction Radial Profile}

Depending on the flow conditions, the void fraction radial profile can present either a peak near the pipe wall or at the center line (Grossetête 1995, Liu 1993, Serizawa et al. 1975, Wang et al. 1987). In their pioneering work, Serizawa et al. (1975) reported that the void fraction radial profile evolves from a wall-peak to a core-peak trend with an increased gas input (see Figure 5a). However, during these experiments the bubble size increased with gas input because a porous injector was used to generate the bubbles (Koide et al. 1968). To study the effect of bubble-size and gas input separately, Liu $(1993,1997)$ used a special gas injector at large liquid-input conditions.
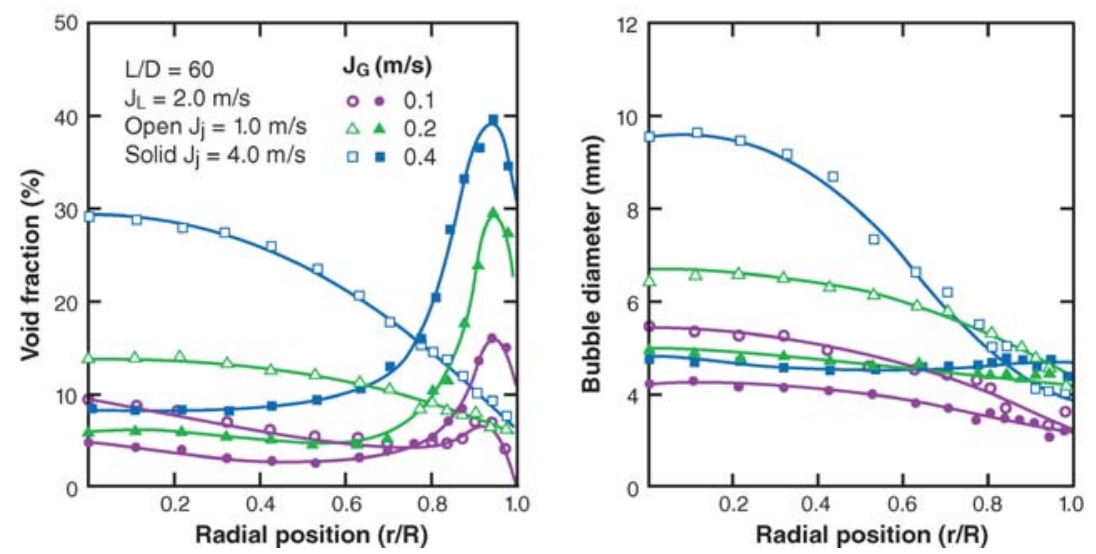

Figure 5

(a) Void fraction profiles measured by Serizawa et al. (1975) in a 60-mm diameter air-water pipe at increased gas input. (b) Void fraction radial profiles in a $57-\mathrm{mm}$ diameter tube and associated bubble-size values (Liu 1997). 
The author showed that the transition from a wall peak to a core peak of void fraction radial profile was dependent on the bubble diameter (Figure $5 \boldsymbol{b}$ ). The observed critical bubble diameter associated with the onset of transition was $D_{b} \approx 5-6 \mathrm{~mm}$ in air-water bubbly pipe flows.

The radial distribution of millimeter-size bubbles is the result of a lift force:

$$
\vec{F}_{\text {lift }}=-C_{l} V_{g} \rho_{l}\left(\vec{U}_{g}-\vec{U}_{l}\right) \times\left(\vec{\nabla} \times \vec{U}_{l}\right),
$$

where $C_{l}$ is the lift-force coefficient, $V_{g}$ is the gas-bubble volume, and $U_{g}$ and $U_{l}$ are the gas and liquid velocity, respectively. $C_{l}=\frac{1}{2}$ is valid for spherical particles or bubbles at large bubble Reynolds number (Auton 1987, Legendre \& Magnaudet 1998, Magnaudet \& Eames 2000, Magnaudet \& Legendre 1998). In general, $C_{l}>0$ for spherical bubbles (Magnaudet \& Legendre 1998), so that small millimeter-size spherical bubbles are pushed toward low liquid velocity regions of the flow and form a wall-peaking void fraction radial profile.

To gain some understanding of the effect of bubble size on the lift force, Tomiyama (1998) and Tomiyama et al. (2002b) reported tracking experiments on a single ellipsoidal bubble placed in a linear shear field. The lift force was obtained by applying a force balance to the measured bubble trajectory. The lift-force coefficient $C_{l}$ was changing sign with an increasing bubble size at increased bubble Reynolds number $\left(R e_{b}>50\right)$ and large Eötvös number. This effect was due to the interactions between the (nonspherical) bubble wake and the shear field. In Figure $\mathbf{6} \boldsymbol{a}$, a series of photos taken by Tomiyama et al. (2002b) clearly illustrates the different transverse motions between a small and a large bubble placed in a linear shear field. Similar results

a

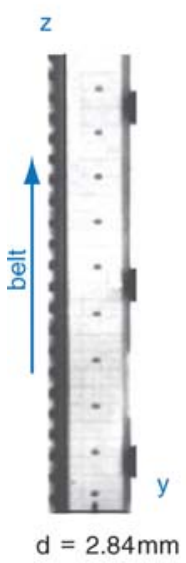

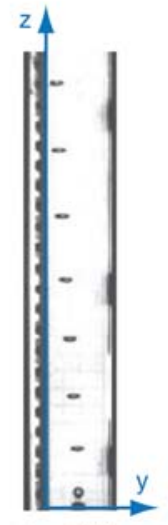

$\mathrm{d}=5.54 \mathrm{~mm}$

\section{b}

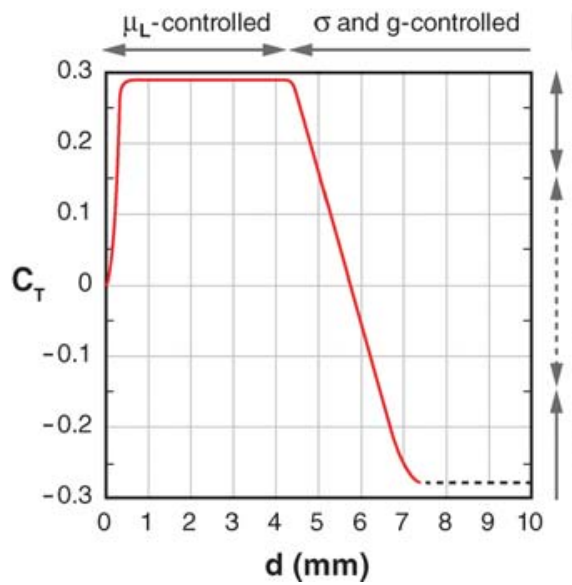

Possible three regimes

Wall regime: $\quad 0.4<\mathrm{d}<5 \mathrm{~mm}$ Migration toward near wall region

Neutral regime: $0<\mathrm{d}<0.4 \mathrm{~mm}$ $5<\mathrm{d}<6 \mathrm{~mm}$ Affected by turbulence, bubble residence time, etc.

Core regime: $\quad 6 \mathrm{~mm}<\mathrm{d}$ Migration toward pipe center

Figure 6

(a) Observations on bubble transverse migration in a linear shear field by Tomiyama et al. (2002b). Depending on the spherical equivalent diameter $D_{b}$, the bubble migrates toward the wall or toward the belt. (b) Model for the transverse lift-force coefficient $C_{T}=C_{l}$ developed by the authors as a function of the spherical equivalent bubble diameter. 
obtained numerically via direct numerical simulation (DNS) studies are reported by Ervin \& Tryggvason (1997), via Lattice-Boltzmann simulations by Sankaranarayanan \& Sundaresan (2002), and for ellipsoidal particles by Gavze \& Shapiro (1997).

The pipe diameter also has an impact on the void fraction profiles in upward bubbly pipe flows. For large-diameter pipes $\left(D_{p}>10 \mathrm{~cm}\right.$ in air-water systems) experimental investigations carried out at moderate to large void fraction conditions mostly report parabolic profiles of void fraction (Mudde \& Saito 2001; Ohnuki \& Akimoto 1996, 2000). However, at low void fractions, and provided that special attention is paid to the bubble injection, a near wall peak of void fraction is also possible in largediameter pipes and bubble columns (Harteveld et al. 2003, Ohnuki \& Akimoto 2000). In addition, at low liquid-input conditions reversed liquid velocities at the wall can be observed similarly to bubble columns (Guet et al. 2004, Mudde \& Saito 2001). This implies a change of the lift-force direction in the near wall boundary, due to a reversed velocity gradient in this area. In large-diameter pipes, this reverse velocitygradient region can be large enough to guarantee a core-peaking radial profile with small bubbles. Bubble dispersion effects due to liquid turbulence also play a significant role in the phase distribution phenomenon when operating with large-diameter pipes (Ohnuki \& Akimoto 2000, 2001).

Investigating the effect of bubble deformation with multiple bubbles is currently becoming accessible via DNS (Bunner \& Tryggvason 2002, 2003; Ervin \& Tryggvason 1997). Also, improved measurement techniques were recently developed to measure bubble deformations and orientation in bubbly shear flows (Fujiwara et al. 2004a,b; Luther et al. 2004; Prasser et al. 2002; Tokuhiro et al. 1998).

\subsection{Flow Pattern Changes}

Four essential flow regimes are commonly distinguished in upward cocurrent vertical pipe flows of a gas and a liquid (Figure 7a): bubbly flow, slug flow, churn flow, and annular flow. Bubbly flow can be separated to two different turbulent subcases:

- The low- to moderate-liquid input bubbly-flow conditions, for which almost no bubble breakup occurs. Under these conditions the bubble size is only influenced by the inlet device and by the entrance conditions (Taitel et al. 1980).

- The finely dispersed bubbly-flow regime, corresponding to large liquid-input conditions. Bubble breakup due to turbulence eddies is dominant. A maximum stable bubble diameter can be connected to the turbulence conditions and surface-tension properties (see Hinze 1959). Although it is beyond the scope of the present review to discuss these aspects in detail, advanced models were recently proposed in the literature to take into account the effect of the dispersed phase fraction on the coalescence rate (Brauner 2001, Chen et al. 1997). Numerous studies also focus on a detailed modeling of the break-up frequency and probability distribution of the bubble or drop size after turbulence breakup (Eastwood et al. 2004, Luo \& Svendsen 1996, Martínez-Bazán et al. 1999, Sarimeseli \& Kelbaliyev 2004). The interested reader is referred to Lasheras et al. (2002) for a review on break-up models. 

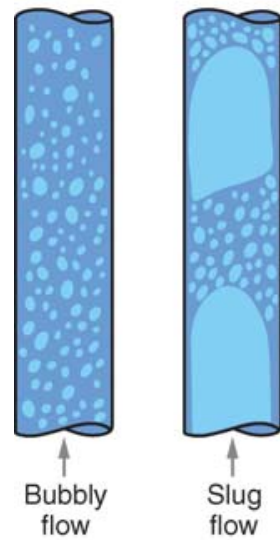

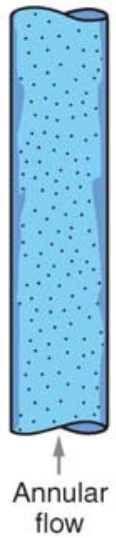

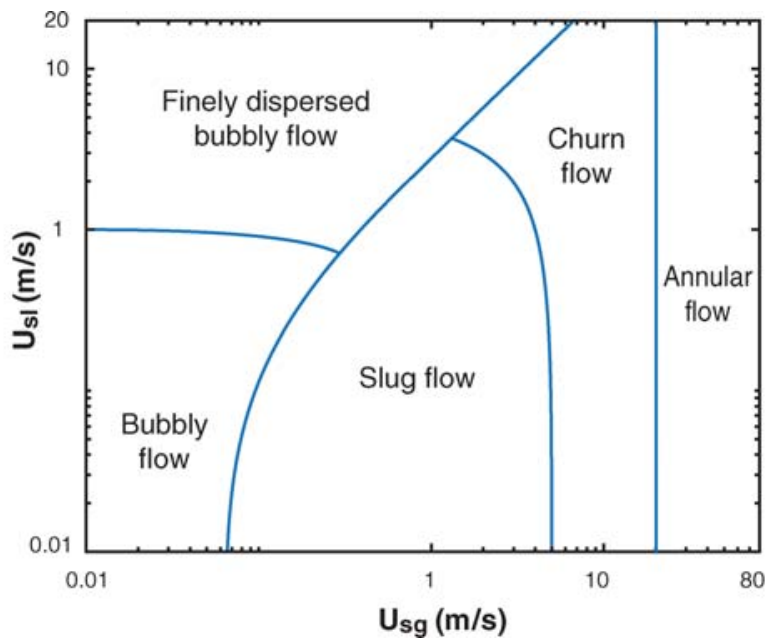

Figure 7

Flow patterns observed in vertical upward bubbly pipe flow (Taitel et al. 1980), and flow pattern map for a 72-mm inner diameter vertical pipe flow of air and water according to the model of Taitel et al. (1980).

At conditions where the gas-lift technique is considered for use, the flow-rate values often correspond to nonfinely dispersed bubbly-flow conditions. The bubbles are injected via a large nozzle injector and the bubble size can vary significantly in such systems. Practically, the flow pattern corresponding to given flow conditions is determined by using a $U_{s g}-U_{s l}$ flow pattern map, as illustrated by the model of Taitel et al. (1980) in Figure $\boldsymbol{7} \boldsymbol{b}$ for an air-water vertical pipe. These maps are based on global flow quantities and can easily be applied to practical situations.

The selection of the appropriate flow pattern is the key to successful pressure predictions because the appropriate modeling approaches are different from one flow pattern to the other. In particular, the bubbly-flow to slug-flow transition is an important issue for gas-lift predictions. It was recently reported that the bubble size has a strong impact on the bubbly-flow to slug-flow transition in air-water systems (Cheng et al. 2002, Guet et al. 2003, Song et al. 1995). For air-water systems with relatively large bubbles $\left(0.05<\frac{D_{b}}{D_{p}}<0.2\right)$ the critical void fraction associated with flow pattern transition is linearly related to the bubble size (Cheng et al. 2002, Guet et al. 2003, Song et al. 1995). A unique relation is valid for a large range of pipe diameters $\left(25 \mathrm{~mm}<D_{p}<72 \mathrm{~mm}\right): \epsilon_{c}=0.55-2.37 \frac{D_{b}}{D_{p}}$.

This result suggests that a constant critical void fraction model, such as $\epsilon_{c}=0.25$ (Taitel et al. 1980) or $\epsilon_{c}=0.3$ (Mishima \& Ishii 1984), cannot be generally valid. However, the effect of bubble size on the bubbly-flow to slug-flow transition in oil has not been investigated in detail in the literature. Based on bubbly-flow to slug-flow transition experiments in viscous fluids, Furukawa \& Fukano (2001) observed that the flow pattern boundary was postponed to larger values of the superficial gas velocity with viscous oil as compared to water. This suggests that coalescence is inhibited 
in oil as compared to water, resulting in larger void fraction $\epsilon_{c}$ associated with flow pattern transition.

\section{BUBBLY PIPE FLOW PREDICTIONS}

To make physically based predictions of large-scale gas-liquid pipe flows such as gas lift, correlations based on the drift-flux model (Zuber \& Findlay 1965) are of practical interest (Guet et al. 2003, Hibiki \& Ishii 2002, Shi et al. 2005). However, to develop such drift-flux correlations, one must consider the flow pattern configuration (Mishima \& Ishii 1984) and details of the phase radial distribution and velocity (Clark et al. 1990, Guet et al. 2004, Hibiki \& Ishii 2003a) by using devoted experiments or by detailed numerical simulation results.

\subsection{Drift-Flux Modeling}

The drift-flux model developed by Zuber \& Findlay (1965) enables one to incorporate the influence of the bubble relative velocity and of the radial profile heterogeneities on the mean void fraction. In particular, this model allows one to consider:

- The nonzero bubble relative velocity, taken into account by the weighted mean drift velocity:

$$
\left|U_{\text {drift }}\right|=\frac{\left\langle\epsilon U_{\text {drift }}\right\rangle}{\langle\epsilon\rangle},
$$

- The (nonhomogeneous) transverse profile of void fraction and phase fluxes. These effects are incorporated by defining a distribution parameter $C_{0}$ :

$$
C_{0}=\frac{\langle\epsilon j\rangle}{\langle\epsilon\rangle\langle j\rangle} .
$$

The operators \langle\rangle and $\|$ represent the area-average value and the void fraction weighted averaging procedure, respectively. $\epsilon$ is the local void fraction and $j$ is the local mixture velocity: $j=j_{g}+j_{l}=\epsilon U_{g}+(1-\epsilon) U_{l}$. $U_{g}$ and $U_{l}$ are the Eulerian gas and liquid velocities and $U_{d r i f t}=U_{g}-j=(1-\epsilon)\left(U_{g}-U_{l}\right)$ is the relative velocity of the bubbles with respect to the local mixture velocity. The area-average mixture velocity $\langle j\rangle$ is given by $\langle j\rangle=U_{m}=U_{s g}+U_{s l}$, and therefore it is determined by available superficial gas and liquid velocity information.

The drift-flux model is generally formulated as $\frac{U_{s g}}{\langle\epsilon\rangle}=C_{0}\langle j\rangle+\left|U_{\text {drift }}\right|$. For gas-lift purpose it can be applied to predict the mean void fraction $\langle\epsilon\rangle$ from the known global quantities $U_{s g}$ and $U_{s l}$ and by using appropriate models for the drift-flux parameters $C_{0}$ and $\left|U_{\text {drift }}\right|$ :

$$
\langle\epsilon\rangle=\frac{U_{s g}}{C_{0}\left(U_{s g}+U_{s l}\right)+\left|U_{d r i f t}\right|} .
$$

The gravitational pressure gradient is then computed by obtaining the mixture density via Equation 2. Therefore, using appropriate drift-flux parameter models is important for proper gas-lift performance predictions. The drift-flux model can also 
be used to quantify separately the gas-lift performance changes due to the effects of the radial heterogeneities and of the relative motion between phases.

The changes in the radial distribution of void fraction due to the bubble-size effects have a strong impact on the gravitational pressure gradient:

- At large liquid-input conditions the transition from a wall-peaking to a corepeaking radial profile of void fraction with increased bubble size leads to changes of the pressure gradient of typically $20 \%$. This is clearly illustrated by reported results on the $C_{0}$ drift-flux distribution parameter (Guet et al. 2004; Hibiki \& Ishii 2002, 2003a). Typical values are $C_{0} \approx 0.95-1$ for a wall-peaking void fraction profile to $C_{0} \approx 1.2$ for a core-peaking radial distribution of void fraction.

- When operating at low liquid-input flow conditions, inverting the liquid velocity profile in the near-wall region implies much larger values of the $C_{0}$ drift-flux parameter because $j_{l}<0$ and eventually $j<0$ in the near-wall region (Clark et al. 1990, Guet et al. 2004, Mudde \& Saito 2001). This leads to significantly large values of the $C_{0}$ parameter $\left(C_{0}>2\right.$ for bubble column flows), and much less efficient gas-lift operations at low liquid-input conditions.

The effects of the flow-pattern or inclination-angle changes can be predicted via the drift-flux model if associated distribution parameter and drift velocity relations are available. The review of Fabre \& Liné (1992) gives extensive details on drift velocity relations for large bubbles in slug flow. Hibiki \& Ishii (2003b) give a large overview of various (semiempirical) drift-flux parameter correlations adapted to a large range of gas-liquid flow patterns, such as bubbly, slug, churn-turbulent, and annular flow.

\subsection{Euler-Euler Modeling of Vertical Upward Bubbly Pipe Flows}

The main difficulties in predicting the hydrodynamic of bubbly pipe flows are due to the coupling between void fraction and velocity radial profiles. To solve this problem, the two-fluid or Euler-Euler modeling approach (Drew 1983, Ishii 1975) is often applied for vertical upward bubbly pipe flow predictions (Chahed \& Masbernat 1998, Drew \& Lahey 1982, Hill et al. 1995, Lopez de Bertodano et al. 1994, Lucas et al. 2001, Politano et al. 2003). In this modeling method both the continuous phase and the dispersed phase are considered as a continuum. The mass and momentum conservation equations are averaged and given in Eulerian coordinates. These averaged equations are given by (Drew 1983):

$$
\begin{aligned}
\frac{\partial\left(\epsilon_{k} \rho_{k}\right)}{\partial t} & +\vec{\nabla} \cdot\left(\epsilon_{k} \rho_{k} \vec{U}_{k}\right)=0, \\
\frac{\partial\left(\epsilon_{k} \rho_{k} \vec{U}_{k}\right)}{\partial t}+\vec{\nabla} \cdot\left(\epsilon_{k} \rho_{k} \vec{U}_{k} \vec{U}_{k}^{t}\right)= & \epsilon_{k} \rho_{k} \vec{g}+\epsilon_{k} \vec{\nabla} \cdot\left(\tau_{k T}\right)-\epsilon_{k} \vec{\nabla} P_{k}+\vec{F}_{k} \\
& +\left(P_{k I}-P_{k}\right) \vec{\nabla} \epsilon_{k}+\left(\tau_{k T}-\tau_{k I}\right) \vec{\nabla} \epsilon_{k},
\end{aligned}
$$

where $k$ denotes the gas or the liquid ( $k=g$ or $l$ ), $\epsilon_{k}$ is the average $k$-phase fraction, and $\boldsymbol{\tau}_{k T}$ is the total stress in phase $k$ (including viscous and turbulence contributions). 
The phases are interacting via interfacial forces $\vec{F}_{k}$ and pressure $P_{k}$. These contributions are included as source terms in the momentum conservation equations. An important issue for modeling vertical upward bubbly pipe flows is the interfacial force:

$$
\vec{F}_{k}=\vec{F}_{k, \text { drag }}+\vec{F}_{k, \text { lift }}+\vec{F}_{k, \text { wall }}+\vec{F}_{k, \text { am }}+\vec{F}_{k, t d},
$$

where $\vec{F}_{d r a g}$ is the drag force, $\vec{F}_{\text {lift }}$ the lift force, $\vec{F}_{\text {wall }}$ a wall force, $\vec{F}_{a m}$ the added mass force, and $\vec{F}_{t d}$ a turbulent dispersion force, which can be included either in the mass or in the momentum conservation equation (Drew 2001). The gravity and drag forces are acting along the $\vec{g}$ vector (in the pipe axial direction). The lift, wall, and turbulent dispersion forces are acting in the pipe radial direction in vertical pipe flows. Therefore, the competition between these forces has an important impact on the void fraction radial profiles. By considering no mass transfer between phases and neglecting surface-tension forces, it is common to assume $\vec{F}_{g}=-\vec{F}_{l}$. For vertical upward bubbly pipe flows, the problem is further simplified to make time-average profile predictions (Antal et al. 1991, Politano et al. 2003).

In this section we use a simplified Euler-Euler model for vertical pipe flows. The assumptions are that of a stationary vertical pipe flow. We further assume that the gravity and stress terms are negligible in the gas phase, due to its low density. In addition, to close the formulation of such a simplified Euler-Euler model, the interfacial forces and pressure jump are expressed on the basis of models available from literature.

4.2.1. Interfacial forces. The drag-force density is given by

$$
\vec{F}_{g, d r a g}=-\frac{3}{8} \frac{\epsilon}{R_{b}} C_{d} \rho_{l}\left(\vec{U}_{g}-\vec{U}_{l}\right)\left|\vec{U}_{g}-\vec{U}_{l}\right|,
$$

where the drag-force coefficient (Ishii \& Zuber 1979) is taken as $C_{d}=\frac{8}{3}(1-\epsilon)^{2}$.

In the frame of the Euler-Euler model and for a preferential direction, fully established cocurrent upward shear flow, the lift force reduces to

$$
\vec{F}_{g, l i f t}=-C_{l} \epsilon \rho_{l}\left|\vec{U}_{g}-\vec{U}_{l}\right| \frac{\partial U_{l}}{\partial r} \vec{e}_{r} .
$$

A local wall force, which drives the bubbles away from the wall was modeled by Antal et al. (1991), following a similarity with lubrication theory. This wall force is expressed as:

$$
\vec{F}_{g, \text { wall }}=-\frac{\epsilon \rho_{l}\left|\vec{U}_{g}-\vec{U}_{l}\right|^{2}}{R_{b}}\left(C_{w 1}+C_{w 2}\left(\frac{R_{b}}{y_{0}}\right)\right) \vec{e}_{r},
$$

where $C_{w 1}=-0.06\left|\vec{U}_{g}-\vec{U}_{l}\right|-0.104, C_{w 2}=0.147$, and $y_{0}=R-r$ is the local distance from the wall. This force is only valid in the near-wall region, and should tend to zero when the distance from the wall increases. It is taken into account for $F_{g, \text { wall }}<0$, i.e, for $r>R+\frac{C_{w 2} R_{b}}{C_{w 1}}$ (Tomiyama 1998, Troshko \& Hassan 2001). This wall force significantly improved a proper near-wall void fraction description: The void fraction decreases toward a value of zero at the wall (experiments also report a decreased void fraction at the wall), whereas two-fluid models based on the lift force only would predict a maximum void fraction value at the wall for small bubbles. 
The turbulence in the liquid tends to redistribute the phase fraction heterogeneities. To model this effect, a turbulence dispersion term is included in the model. Contrary to microscopic diffusion terms included in the mass conservation equation, this effect is taken into account by an additional turbulent dispersion force in the momentum conservation equation (Drew 2001, Moraga et al. 2003). Following a diffusion approach, this force (Carrica et al. 1999, Hill et al. 1995, Politano et al. 2003, Troshko \& Hassan 2001) is modeled as:

$$
\vec{F}_{g, t d}=-\frac{3}{8} \rho_{l} v_{t} \frac{C_{d}}{R_{b}}\left|\vec{U}_{g}-\vec{U}_{l}\right| \frac{\partial \epsilon}{\partial r}
$$

$v_{t}$ is the turbulent viscosity, taken from Sato et al.'s (1981) model:

$$
v_{t}=v_{t_{0}}+v_{t_{b}},
$$

where $v_{t_{0}}=\frac{K R u_{L}^{*}}{6}\left(1-r^{* 2}\right)\left(1+2 r^{* 2}\right) f\left(y^{+}\right)$(Reichardt 1951) is the wall-friction part. The contribution due to bubble-induced turbulence is taken as $v_{t_{b}}=$ $k_{1} \in R_{b}\left|\vec{U}_{g}-\vec{U}_{l}\right| f\left(y^{+}\right)$(Sato et al. 1981). A wall damping function $f\left(y^{+}\right)$as proposed by van Driest (1956) is used to achieve a realistic eddy viscosity prediction in the near-wall region.

4.2.2. Interfacial pressure. The averaged interfacial pressures $P_{l I}$ and $P_{g I}$ need to be related to the spatial average of the pressure. Near the bubble surface, the liquid velocity is larger than the far field velocity. This results in a pressure difference, approximated by a potential flow solution:

$$
P_{l I}-P_{l}=-C_{p} \rho_{l}(1-\epsilon)\left|\vec{U}_{g}-\vec{U}_{l}\right|^{2} .
$$

In this expression the coefficient $C_{p}=\frac{1}{4}$ is valid for spherical bubbles (Stuhmiller 1977). Contrary to the liquid phase, in the gas phase this pressure difference is neglected due to the low density, therefore $P_{g}-P_{l}=P_{l I}-P_{l}$.

4.2.3. A simplified Euler-Euler model. Following the assumptions, the gas and the liquid radial momentum conservation equations are given by (see also Antal et al. 1991 and Politano et al. 2003):

$$
\begin{gathered}
\frac{\partial P_{g}}{\partial z}=\rho_{g} g-\frac{3}{8} \frac{1}{R_{b}} C_{d} \rho_{l} U_{r}{ }^{2}, \\
\epsilon \frac{\partial P_{g}}{\partial r}=-C_{l} \epsilon \rho_{l} U_{r} \frac{\partial U_{l}}{\partial r}-\frac{\epsilon \rho_{l} U_{r}^{2}}{R_{b}}\left[C_{w 1}+C_{w 2}\left(\frac{R_{b}}{R-r}\right)\right]-\frac{3}{8} \mu_{t} \frac{C_{d}}{R_{b}} U_{r} \frac{\partial \epsilon}{\partial r}, \\
(1-\epsilon) \frac{\partial P_{l}}{\partial z}=(1-\epsilon) \frac{1}{r} \frac{\partial}{\partial r}\left[r\left(\mu_{l}+\mu_{t}\right) \frac{\partial U_{l}}{\partial r}\right]+(1-\epsilon) \rho_{l} g+\frac{3}{8} \frac{\epsilon}{R_{b}} C_{d} \rho_{l} U_{r}{ }^{2},
\end{gathered}
$$

and

$$
\begin{aligned}
(1-\epsilon) \frac{\partial P_{l}}{\partial r}= & C_{p} \rho_{l} U_{r}^{2}(1-\epsilon) \frac{\partial \epsilon}{\partial r}+C_{l} \epsilon \rho_{l} U_{r} \frac{\partial U_{l}}{\partial r} \\
& +\frac{\epsilon \rho_{l} U_{r}^{2}}{R_{b}}\left[C_{w 1}+C_{w 2}\left(\frac{R_{b}}{R-r}\right)\right]+\frac{3}{8} \mu_{t} \frac{C_{d}}{R_{b}} U_{r} \frac{\partial \epsilon}{\partial r}
\end{aligned}
$$


By combining the two equations for the radial momentum and using the pressure jump relation (Equation 16), a simple ordinary differential equation is obtained for the void fraction:

$$
\frac{\partial \epsilon}{\partial r}=\frac{-C_{l} \rho_{l} U_{r} \frac{\partial U_{l}}{\partial r} \epsilon-\frac{\epsilon \rho l}{R_{r}^{2}}\left(C_{w 1}+C_{w 2} \frac{R_{b}}{R-r}\right)}{\epsilon(1-\epsilon) 2 C_{p} \rho_{l} U_{r}^{2}+\frac{3}{8} \mu_{t} \frac{C_{d}}{R_{b}} U_{r}}=\frac{F_{g, l}+F_{g, w}}{D} .
$$

This expression clearly illustrates that the presence of a peak of void fraction is only observed when there is a competition between the wall and the lift force because the denominator $D$ of Equation 21 is by definition positive. The wall force is by definition negative, therefore a wall peak of void fraction is found if the lift force is positive. Based on their experiments, Tomiyama et al. (2002b) developed a model for the liftforce coefficient $C_{l}$. For intermediate range bubble diameter $\left(4<E_{o_{d}}<10.7\right)$, it is given by

$$
C_{l}=f\left(E_{o_{d}}\right)=0.00105 E_{o_{d}}^{3}-0.0159 E_{o_{d}}^{2}-0.0204 E_{o_{d}}+0.474,
$$

where $E_{o_{d}}$ is a modified Eötvös number based on the horizontal chord length of the bubble $D_{H}\left(E_{o_{d}}=\frac{g\left(\rho_{l}-\rho_{g}\right) D_{H}{ }^{2}}{\sigma}\right)$. This lift-force coefficient is depicted as a function of the equivalent diameter of an air bubble in water in Figure $\mathbf{6} \boldsymbol{b}$. This result suggests the lift-force coefficient $C_{l}$ becomes negative for large bubbles. Tomiyama et al. (2002b) reported that the value of the critical single-bubble diameter associated with the onset of transverse migration in a linear shear field corresponds surprisingly well to the reported critical bubble size value associated with wall-to-core peak void fraction radial profile transition in vertical pipes. Therefore, the model developed by Tomiyama et al. (2002b) for the lift-force changes with increased bubble size was recently successfully applied to predict the void fraction profile changes in vertically oriented bubbly pipe flows by using an Eulerian approach (Lucas et al. 2001, Politano et al. 2003).

In Figure 8 we compare void fraction profiles from experiments with predictions via our simplified model (Guet et al. 2004); here $D_{b}=4 \mathrm{~mm}$ and $D_{b}=8 \mathrm{~mm}$ and the liquid input is moderate, corresponding to $R e_{s l}=16000$. The relation suggested by Tomiyama et al. (2002b) for the lift-force coefficient is used in the model. Clearly, this lift-force coefficient relation enables one to reasonably describe the changes of void fraction radial profiles observed during these flow conditions, which are representative of gas-lift application. Similar numerical predictions for various pipe diameters and at large liquid-input conditions can be found in Lucas et al. (2001) and Politano et al. (2003). It should, however, be noted that the above lift-force model does not take into account bubble-bubble interactions and the local effect of the bubbles on the shear field. As Tomiyama et al. (2002b) suggested, further research is needed to develop more accurate models for large void fraction, turbulent bubbly pipe flow predictions.

In order to make physically based predictions of large-scale gas-liquid pipe flows such as gas-lift applications, a two-fluid model such as the one suggested above can be used to develop drift-flux correlations. For example, a comparison between direct 


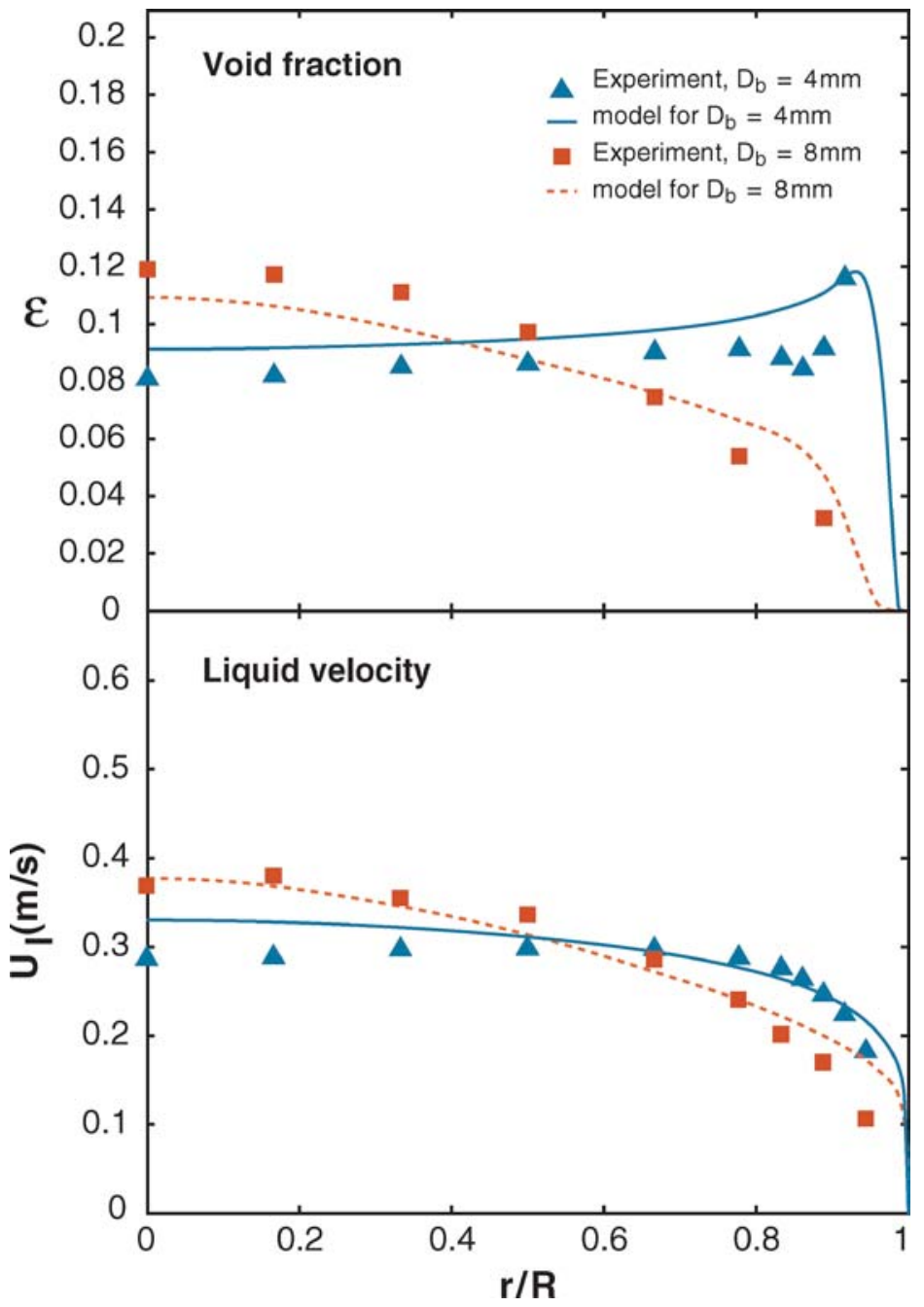

$C_{0}$ parameter measurements and $C_{0}$ predictions is depicted in Figure 9. The $C_{0}$ parameter was obtained by applying Equation 6 to both the measurements and to the numerical predictions of air-water vertical pipe flows. The typical changes of the $C_{0}$ parameter with bubble diameter are similar in the experiments and in the simulations: from typically $C_{0} \approx 0.95$ for the wall-peaking radial distribution of void fraction to $C_{0} \approx 1.2$ for the parabolic radial distribution of void fraction associated with large bubbles. This result shows changes in the volumetric average void fraction of typically $20 \%$ due to the void-fraction radial profiles. Such results are also confirmed by direct pressure gradient measurements and airlift experiments (François et al. 1996, Guet et al. 2003).
Figure 8

Results obtained for a 72-mm inner diameter pipe flow at $R e_{s l}=16000$, and for $D_{b}=4$ and $8 \mathrm{~mm}$ : void fraction and liquid velocity. The model results are compared with experiments. 
Figure 9

Distribution parameter as a function of the spherical equivalent bubble diameter: simulation results and experimental data (Guet et al. 2004).

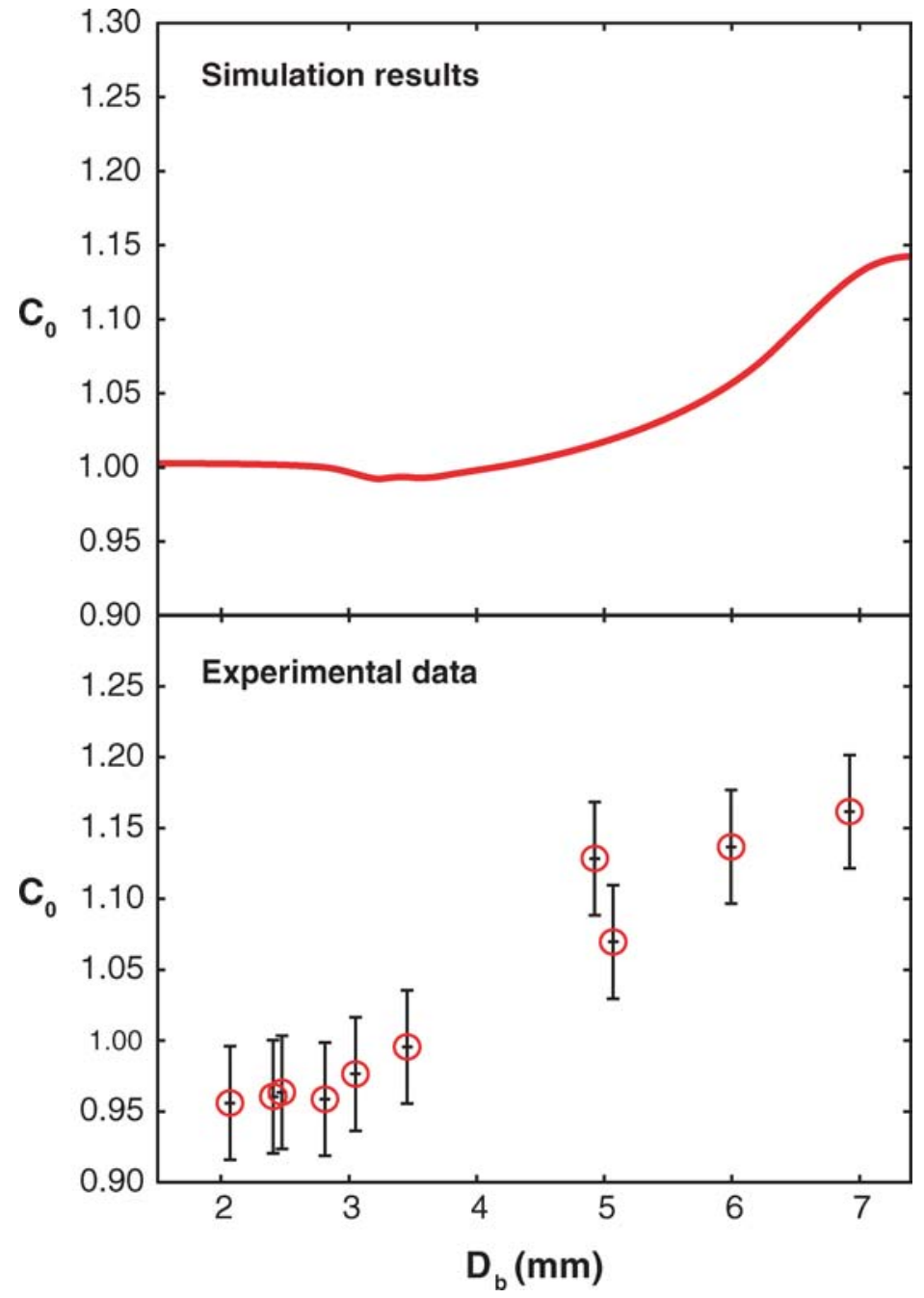

\section{DISCUSSION AND PERSPECTIVES}

\subsection{Gas-Lift Optimization}

As mentioned earlier, a critical parameter for gas-lift efficiency determination is the bubble size. Decreasing the bubble size permits one to postpone the bubblyflow to slug-flow transition to a larger value of the critical void fraction and to operate at wall-peaking radial void fraction profile conditions (which is beneficial for gas lift, as illustrated by the associated decreased $C_{0}$ drift-flux parameter value). It also increases the bubble residence time by reducing the bubble relative velocity. 
Although the height of the tubing is relatively large in gas-lift practice $(H \approx 1 \mathrm{~km})$, the changes in pressure from bottom to top are not very significant since the tube is pressurized from the top (typical pressure conditions are $P_{B H P} \approx 100$ bars and $P_{\text {top }} \approx 20$ bars). Therefore, the bubble size does not change significantly from the bottom to the top of the well, and in principle it is possible to ensure wall-peaking void fraction profiles at any vertical position on the pipe.

To guarantee a reduced bubble size, it is therefore important to find ways of controlling the bubble formation process and of keeping the bubbles small enough by avoiding coalescence or by increasing bubble breakup. To generate small bubbles, a number of injection devices were tested in the literature.

5.1.1. Bubble generator configuration. To decrease the initial size of the bubbles, one can use a porous surface to generate the bubbles (Higushi et al. 1998, Koide et al. 1968). A grid can be placed downstream from the porous area to avoid recoalescence at large gas-input conditions (Koide et al. 1968). The bubble size can further be reduced by using a rotating porous cylinder to locally increase the shear force. Such injectors guarantee very small bubbles (Chiba \& Takahashi 1998, Fujikawa et al. 2003). Also, Kawamura et al. (2004) recently showed that it is possible to guarantee submillimeter bubble size by using a Venturi-shaped nozzle. This technique, based on bubble breakup by a pressure wave, is a promising item for gas-lift application because in principle it is free of moving parts.

5.1.2. Bubble coalescence and formation process. The mechanism by which bubbles coalesce can be described as follows (Oolman \& Blanch 1985): If two bubbles are in contact during a time $t_{\text {cont }}>t_{\text {crit }}$, the film between the two interfaces will drain and the interfaces will merge due to the film-thinning process. This will lead to bubble coalescence. It is therefore possible to influence coalescence by acting directly on the gas-liquid interface. To this end, two approaches are possible: interface properties can be changed by using additives in the liquid phase and dynamic control can be used.

The interfacial properties can be changed by adding surfactants to the liquid phase. The critical time for coalescence is related to the surface-tension properties of the gas-liquid interface (Oolman \& Blanch 1985). After observing the coalescence of a bubble pair in quiescent liquids, Duineveld (1998) reported that the coalescence of bubbles was governed by the Weber number $W_{e}=\frac{\rho V^{2} R_{b}}{\sigma}$, based on the bubbles velocity of approach $V$; below $W e_{c}=0.18$, the bubbles coalesced. If the surfactant concentration was above a certain limit, coalescence was never observed. In addition to coalescence prevention in this situation, the bubble size as generated by the injector is reduced, both for nozzles (Hsu et al. 2000) and porous injectors (Koide et al. 1968). As a result, performances of airlifts and bubble columns are significantly improved by adding surfactants (Al-Masry \& Dukkan 1997, Chen \& Lee 1999).

Another technique for reducing the bubble size is the use of ionic solutions, such as saline. For instance, with salt added to water, the frequency of bubbles generated both at an orifice and at the surface of a porous surface increases (Hofmeier et al. 1995, Slauenwhite \& Johnson 1999). Available literature reports a different dynamics 
of the bubble formation process in salt water as compared to tap water. Whereas in tap water the bubble feeding phenomena is observed (i.e., a bubble coalesces with the preceding bubble at the nozzle exit when the gas input is increased), bouncing is reported for salt water (Hofmeier et al. 1995). In this situation multiple streams of reduced-size bubbles are observed when for the same conditions a single stream of large bubbles is observed with water (Hofmeier et al. 1995). However, the mechanisms responsible for this effect are not completely understood. Possible explanations are increased local repulsion forces due to interfacial polarization or local gradients of ions concentration resulting in surface-tension gradients (the Marangoni effect).

To reduce bubble coalescence, it is also possible to actively control the gasliquid interface. Applying mechanical vibrations significantly reduces the bubble size (Ellenberger \& Krishna 2003, Krishna \& Ellenberger 2002). The main effect of such vibrations is the disappearance of bubble coalescence in the vicinity of the bubble injector. It is also possible to use acoustics to prevent bubbles from coalescing: By applying an acoustic wave with a frequency near to the bubble resonance value, Duineveld (1996) reported bubble shape oscillations and observed no coalescence. In addition, applying an acoustic wave can potentially allow bubble displacement toward preferred regions of the flow (Abe et al. 2002).

\subsection{Concluding Remarks}

The gas-lift technique is influenced by a number of fluid-flow phenomena. In particular, the flow pattern, phase distribution, and phase-relative motions are important effects. More generally, these mechanisms are important for determining the gravitational pressure; therefore, it is a significant issue for many more practical gas-liquid flow applications, such as airlifts, bubble column mixers, or for the security of nuclear installations. In particular, the effects of bubble deformation on the hydrodynamics of bubbly shear flows and the coalescence mechanism are interesting subjects of research both from a fundamental point of view and for the optimization of the gas-lift technique.

\section{ACKNOWLEDGMENTS}

Financial support was provided by the European Research Network on Nonideal Turbulence (contract HPRN-CT-200000162). We thank Detlef Lohse, Rob Mudde, and René Oliemans for their continuous interest in this project. We are grateful to Leen van Wijngaarden for his detailed comments on the manuscript.

\section{LITERATURE CITED}

Abe Y, Kawaji M, Watanabe T. 2002. Study of the bubble motion control by ultrasonic wave. Exp. Therm. Fluid Sci. 26:817-26

Al-Masry WA, Dukkan AR. 1997. The role of gas disengagement and surface active agents on hydrodynamics and mass transfer characteristics of airlift reactors. Chem. Eng. 7. 65:263-71 
Antal SP, Lahey RT, Flaherty JE. 1991. Analysis of phase distribution in fully developed laminar bubbly two phase flow. Int. 7. Multiph. Flow 7:635-52

Apazidis N. 1985. Influence of bubble expansion and relative velocity on the performances and stability of an airlift pump. Int. F. Multiph. Flow 4:459-79

Auton TR. 1987. The lift force on a spherical body in a rotational flow. F. Fluid Mech. 183:199-257

Batchelor GK. 1989. A brief guide to two phase flow. In Theoretical and Applied Mechanics, ed. P Germain, M Piau, D Caillerie, pp. 27-40. Amsterdam: Elsevier

Bertuzzi AF, Welchon JK, Poetmann FH. 1953. Description and analysis of an efficient continuous gas-lift installation. Pet. Trans. AIME 198:271-78

Brauner N. 2001. The prediction of dispersed flow boundaries in liquid-liquid and gas-liquid systems. Int. F. Multiph. Flow 27:885-910

Bunner B, Tryggvason G. 2002. Dynamics of homogeneous bubbly flows. Part 1 . Rise velocity and microstructure of the bubbles. F. Fluid Mech. 466:17-52

Bunner B, Tryggvason G. 2003. Effect of bubble deformation on the properties of bubbly flows. 7. Fluid Mech. 495:77-118

Carrica PM, Drew D, Bonetto F, Lahey RT Jr. 1999. A polydisperse model for bubbly two-phase flow around a surface ship. Int. F. Multiph. Flow 25:257-305

Chahed J, Masbernat L. 1998. Effet de parois sur la distribution de taux de vide dans les écoulements à bulles. C. R. Acad. Sci. 326(2b):719-26

Chen XT, Cai XD, Brill JP. 1997. A general model for transition to dispersed bubble flow. Chem. Eng. Sci. 52:4373-80

Chen LH, Lee YL. 1999. Surfactant effects on the equipment performance of extraction columns. F. Chem. Eng. Fpn. 32:138-41

Cheng H, Hills JH, Azzorpardi BJ. 2002. Effect of initial bubble size on flow pattern transition in a $28.9 \mathrm{~mm}$ diameter column. Int. F. Multiph. Flow 28:1047-62

Chiba N, Takahashi Y. 1998. Generation of micro air bubbles of uniform size in water. Presented at Third Int. Symp. Cavitation, Grenoble, France

Clark NN, Egmond JW, van Nebiolo EP. 1990. The drift-flux model applied to bubble columns and low velocity flows. Int. 7. Multiph. Flow 16:261-79

Clift R, Grace JR, Weber ME. 1978. Bubbles, Drops and Particles. New York: Academic

Drew DA, Lahey RT. 1982. Phase distribution mechanisms in turbulent low-quality two-phase flow in a circular pipe. F. Fluid Mech. 117:91-106

Drew DA. 1983. Mathematical-modeling of 2-phase flow. Annu. Rev. Fluid Mech. 15:261-91

Drew DA. 2001. A turbulent dispersion model for particles or bubbles. F. Eng. Math. 41:259-74

Duineveld PC. 1996. The influence of an applied sound field on bubble coalescence. 7. Acoust. Soc. Am. 99:622-24

Duineveld PC. 1998. Bouncing and coalescence of bubble pairs rising at high Reynolds number in pure water or aqueous surfactant solutions. Appl. Sci. Res. 58:409-39

Eames I, Hunt JCR, Belcher SE. 2004. Inviscid mean flow through and around groups of bodies. F. Fluid Mech. 515:371-89

Eastwood CD, Armi L, Lasheras JC. 2004. The breakup of immiscible fluids in turbulent flows. F. Fluid Mech. 502:309-33 
Ervin EA, Tryggvason G. 1997. The rise of bubbles in a vertical shear flow. F. Fluid Eng. 119:443-49

Ellenberger J, Krishna R. 2003. Shaken, not stirred, bubble column reactors: enhancement of mass transfer by vibration excitement. Chem. Eng. Sci. 58:705-10

Fabre J, Liné A. 1992. Modeling of two-phase slug flow. Annu. Rev. Fluid Mech. 24:21-46

François O, Gilmore T, Pinto MJ, Gorelick SM. 1996. A physically based model for air-lift pumping. Water Resour. Res. 32:2383-99

Fujikawa S, Zhang R, Hayama S, Peng G. 2003. The control of micro-air-bubble generation by a rotational porous plate. Int. 7. Multiph. Flow 29:1221-36

Fujiwara A, Danmoto Y, Hishida K, Maeda M. 2004a. Bubble deformation and flow structure measured by double shadow images and PIV/LIF. Exp. Fluids 36:15765

Fujiwara A, Minato D, Hishida K. 2004b. Effect of bubble diameter on modification of turbulence in an upward pipe flow. Int. F. Heat Fluid Flow 25:481-88

Furukawa T, Fukano T. 2001. Effects of liquid viscosity on flow patterns in vertical upward gas-liquid two-phase flow. Int. F. Multiph. Flow 27:1109-26

Garnier C, Lance M, Marié JL. 2002. Measurement of local flow characteristics in buoyancy-driven bubbly flow at high void fraction. Exp. Therm. Fluid Sci. 26:811-15

Gavze E, Shapiro M. 1997. Particles in a shear flow near a solid wall: effect of nonsphericity on forces and velocities. Int. F. Multiph. Flow 23:155-82

Grossetête C. 1995. Experimental investigation of void profile development in a vertical cylindrical pipe. Proc. Second Int. Conf. Multiph. Flow, Kyoto, Japan

Guet S, Ooms G, Oliemans RVA, Mudde RF. 2003. Bubble injector effect on the gaslift efficiency. AICbE 7. 49:2242-52

Guet S, Ooms G, Oliemans RVA, Mudde RF. 2004. Bubble size effect on low liquid input drift-flux parameters. Chem. Eng. Sci. 59:3315-29

Harteveld WK, Mudde RF, Van den Akker HEA. 2003. Dynamics of a bubble column: influence of gas distribution on coherent structures. Can. 7. Chem. Eng. 81:38994

Hibiki T, Ishii M. 2002. Distribution parameter and drift velocity of drift-flux model in bubbly flow. Int. 7. Heat Mass Transf. 45:707-21

Hibiki T, Ishii M. 2003a. One dimensional drift-flux model for two-phase flow in a large diameter pipe. Int. 7. Heat Mass Transf. 46:1773-90

Hibiki T, Ishii M. 2003b. One-dimensional drift-flux model and constitutive equations for relative motion between phases in various two-phase flow regimes. Int. 7. Heat Mass Transf. 46:4935-48

Higushi M, Kaji M, Morita ZI. 1998. Effect of pore diameter, bath surface pressure, and nozzle diameter on the bubble formation from a porous nozzle. Metall. Mater. Trans. B 29b:1209-18

Hill DP, Wang DM, Gosman AD, Issa RI. 1995. Numerical prediction of two-phase bubbly flow in a pipe. Proc. Second Int. Conf. Multiph. Flow, Kyoto, Japan

Hinze JO. 1959. Turbulence. New York: McGraw-Hill

Hofmeier U, Yaminsky VV, Christenson HK. 1995. Observations of solute effects on bubble formation. F. Colloid Interface Sci. 174:199-210 
Hsu SH, Lee WH, Yang YM, Chang CH, Maa JR. 2000. Bubble formation at an orifice in surfactant solutions under constant flow conditions. Ind. Eng. Chem. Res. 39:1473-79

Hu B, Golan M. 2004. Dynamic simulator predicts gas lift well instability. F. Pet. Technol. 56:53-54

Ishii M. 1975. Thermo-Fluid Dynamic Theory of Two-Phase Flow. Paris: Eyrolles

Ishii M, Zuber N. 1979. Drag coefficient and relative velocity in bubbly, droplet or particulate flows. AICbE 7. 25:843-55

Kawamura T, Sakamoto J, Motoyama H, Kato H, Miyanaga M. 2004. Experimental study on the effect of bubble size on the microbubble drag reduction. Proc. Int. Conf. Multiph. Flow, ICMF5, Yokohama, Japan

Koide K, Kato S, Tanaka Y, Kubota H. 1968. Bubble generated from porous plate. 7. Chem. Eng. 7pn. 5:51-56

Kowe R, Hunt JCR, Hunt A, Couet B, Bradbury LJS. 1988. The effects of bubbles on the volume fluxes and the pressure gradients in unsteady and non uniform flow of liquids. Int. F. Multiph. Flow. 14:587-606

Krishna R, Ellenberger J. 2002. Improving gas-liquid contacting in bubble columns by vibration excitement. Int. F. Multiph. Flow. 7:1223-34

Lasheras JC, Eastwood C, Martínez-Bazán C, Montañes JL. 2002. A review of statistical models for the break-up of an immiscible fluid immersed into a fully developed turbulent flow. Int. F. Multiph. Flow. 28:247-78

Legendre D, Magnaudet J. 1998. The lift force on a spherical bubble in a viscous linear shear flow. F. Fluid Mech. 368:81-126

Lin PY, Hanratty TJ. 1989. Detection of slug flow from pressure measurements. Int. 7. Multiph. Flow 13:13-21

Liu TJ. 1993. Bubble size and entrance length effects on void development in a vertical channel. Int. 7. Multiph. Flow 19:99-113

Liu TJ. 1997. Investigation of the wall shear stress in vertical bubbly flow under different bubble size conditions. Int. F. Multiph. Flow 23:1085-109

Lopez de Bertodano M, Lahey RT, Jones OC. 1994. Phase distribution in bubbly two-phase flow in vertical ducts. Int. 7. Multiph. Flow 20:805-18

Lucas D, Krepper E, Prasser HM. 2001. Prediction of radial gas profiles in vertical pipe flow on the basis of bubble size distribution. Int. F. Therm. Sci. 40:217-25

Luo H, Svendsen HF. 1996. Theoretical model for drop and bubble breakup in turbulent dispersions. AIChE 7. 42:1225-33

Luther S, Rensen J, Guet S. 2004. Bubble aspect ratio and velocity measurement using a four-point fiber-optical probe. Exp. Fluids 36:326-33

Magnaudet J, Legendre D. 1998. Some aspects of the lift force on a spherical bubble. Appl. Sci. Res. 58:441-61

Magnaudet J, Eames I. 2000. The motion of high-Reynolds-number bubbles in inhomogeneous flows. Annu. Rev. Fluid Mech. 32:659-708

Martínez-Bazán C, Montañés JL, Lasheras JC. 1999. On the breakup of an air bubble injected into a fully developed turbulent flow. Part 1 . Breakup frequency. F. Fluid Mech. 401:157-82

Mishima K, Ishii M. 1984. Flow regime transition criteria for upward two-phase flow in vertical tubes. Int. F. Heat Mass Transf. 27:723-37 
Moraga FJ, Larreteguy AE, Drew DA, Lahey RT Jr. 2003. Assessment of turbulent dispersion models for bubbly flows in the low Stokes number limit. Int. 7. Multiph. Flow 29:655-73

Mudde RF, Saito T. 2001. Hydrodynamical similarities between bubble column and bubbly pipe flow. F. Fluid Mech. 437:203-28

Ohnuki A, Akimoto H. 1996. An experimental study on developing air-water two phase flow along a large diameter pipe: effect of air injection method. Int. 7 . Multiph. Flow 22:1143-54

Ohnuki A, Akimoto H. 2000. Experimental study on transition of flow pattern and phase distribution in upward air-water two-phase flow along a large vertical pipe. Int. F. Multiph. Flow 26:367-86

Ohnuki A, Akimoto H. 2001. Model development for bubble turbulent diffusion and bubble diameter in large vertical pipes. F. Nucl. Sci. Technol. 38:1074-80

Oolman TO, Blanch HW. 1985. Bubble coalescence in stagnant liquids. Chem. Eng. Commun. 43:237-61

Pennington H. 1927. Lift efficiency depends upon skill in design and operation. Oil Wkly. 19:41-82

Poetmann FH, Carpenter PG. 1952. The multi-phase flow of gas, oil and water through vertical flow strings. Drill. Prod. Pract. 257:257-317

Politano MS, Carrica PM, Converti J. 2003. A model for turbulent polydisperse-two phase flow in vertical channels. Int. 7. Multiph. Flow. 29:1153-82

Prasser HM, Krepper E, Lucas D. 2002. Evolution of the two-phase flow in a vertical tube-decomposition of gas fraction profiles according to bubble size classes using wire-mesh sensors. Int. 7. Therm. Sci. 41:17-28

Reichardt H. 1951. Vollstandige darstellung der turbulenten geschwindigkeittsverteilung in glatten leitungen. ZAMM 31:208-19

Richardson JF, Zaki WN. 1954. Sedimentation and fluidization: Part 1. Trans. Instr. Chem. Eng. 32:35-53

Rivière N, Cartellier A. 1999. Wall shear stress and void fraction in poiseuille bubbly flows: Part 1: simple analytic predictions. Eur. F. Mech. Vol. B/Fluids 18:823-46

Ros NCJ. 1961. Simultaneous flow of gas and liquid as encountered in well tubing. 7. Pet. Technol. Oct.:1037-49

Sankaranarayanan K, Sundaresan S. 2002. Lift force in bubbly suspensions. Chem. Eng. Sci. 57:3521-42

Sarimeseli A, Kelbaliyev G. 2004. Modeling of the break-up of deformable particles in developed turbulent flow. Int. 7. Multiph. Flow 59:1233-40

Sato Y, Sadatomi L, Sekogushi K. 1981. Momentum and heat transfer in two phase bubbly flow. Int. F. Multiph. Flow 7:167-90

Serizawa A, Kataoka I, Michiyoshi I. 1975. Turbulence structure of air-water bubbly flows - 2. Local properties. Int. 7. Multiph. Flow 2:235-46

Shi H, Holmes JA, Durlofsky LJ, Aziz K, Diaz LR, et al. 2005. Drift-flux modeling of multiphase flow in wellbores. Soc. Petr. Eng. SPE 84228-PA, 10:24-33

Slauenwhite DE, Johnson BD. 1999. Bubble shattering: differences in bubble formation in fresh water and sea water. F. Geophys. Res. C 104:3265-75 
Song CH, No HC, Chung MK. 1995. Investigation of bubble flow developments and its transition based on the instability of void fraction waves. Int. F. Multiph. Flow. 21:381-404

Stuhmiller JH. 1977. The influence of interfacial pressure forces on the character of two-phase flow model equations. Int. F. Multiph. Flow 3:551-60

Taitel Y, Barnea D, Dukler AE. 1980. Modeling flow pattern transitions for steady upward gas-liquid flow in vertical tubes. AICbE 7. 26:345-54

Tokuhiro A, Maekawa M, Iizuka K, Hishida K, Maeda M. 1998. Turbulent flow past a bubble and an ellipsoid using shadow-image and PIV techniques. Int. F. Multiph. Flow 24:1383-406

Tomiyama A. 1998. Struggle with computational bubble dynamics. Third Int. Conf. Multiph. Flow, Lyon, France

Tomiyama A, Tamai H, Celata GP, Hosokawa S, Yoshida S. 2002a. Terminal velocity of single bubbles in surface tension force dominant regime. Int. F. Multiph. Flow 28:1497-519

Tomiyama A, Tamai H, Zun I, Hosokawa S. 2002b. Transverse migration of single bubbles in simple shear flow. Chem. Eng. Sci. 57:1849-58

Troshko AA, Hassan YA. 2001. A two-equation turbulence model of turbulent bubbly flow. Int. F. Multiph. Flow 27:1965-2000

Tutu N. 1982. Pressure fluctuations and flow pattern recognition in vertical two-phase gas-liquid flows. Int. 7. Multiph. Flow. 8:443-47

Tutu N. 1984. Pressure drop fluctuations and bubble-slug transition in a vertical two phase air-water flow. Int. F. Multiph. Flow 10:211-16

van Driest ER. 1956. On turbulent flow near a wall. F. Aeron. Sci. 23:1007-11

van Wijngaarden L. 1991. Bubble deformation in bubbly liquids and its effect on the stability of void fraction waves. In Mathematical Approaches in Hydrodynamics, pp. 39-49 Philadelphia: SIAM

van Wijngaarden L. 1993. The mean rise velocity of pairwise-interacting bubbles in liquid. F. Fluid Mech. 251:55-78

Wang SK, Lee SJ, Jones OC, Lahey RT Jr. 1987. 3-D turbulence structure and phase distribution measurements in bubbly two-phase flow. Int. F. Multiph. Flow $13: 327-43$

Zenit R, Koch DL, Sangani A. 2001. Measurements of the average properties of a suspension of bubbles rising in a vertical channel. F. Fluid Mech. 429:307-41

Zuber N, Findlay JA. 1965. Average volumetric concentration in two-phase flow systems. 7. Heat Transf. Trans. ASME 87:453-68 


\section{Contents}

Annual Review of

Fluid Mechanics

Volume 38, 2006

Nonlinear and Wave Theory Contributions of T. Brooke Benjamin

(1929-1995)

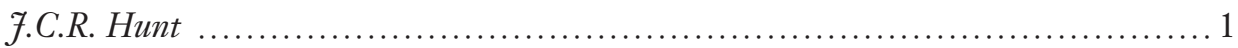

Aerodynamics of Race Cars

Foseph Katz

Experimental Fluid Mechanics of Pulsatile Artificial Blood Pumps

Steven Deutsch, Fobn M. Tarbell, Keefe B. Manning, Gerson Rosenberg, and Arnold A. Fontaine

Fluid Mechanics and Homeland Security

Gary S. Settles

Scaling: Wind Tunnel to Flight

Dennis M. Bushnell

Critical Hypersonic Aerothermodynamic Phenomena John 7. Bertin and Russell M. Cummings

Drop Impact Dynamics: Splashing, Spreading, Receding, Bouncing...

A.L. Yarin

Passive and Active Flow Control by Swimming Fishes and Mammals F.E. Fish and G.V. Lauder

Fluid Mechanical Aspects of the Gas-Lift Technique

S. Guet and G. Ooms

Dynamics and Control of High-Reynolds-Number Flow over Open

Cavities

Clarence W. Rowley and David R. Williams .....

Modeling Shapes and Dynamics of Confined Bubbles

Vladimir S. Ajaev and G.M. Homsy

Electrokinetic Flow and Dispersion in Capillary Electrophoresis

Sandip Ghosal.

Walking on Water: Biolocomotion at the Interface

Fohn W.M. Bush and David L. Hu 
Biofluidmechanics of Reproduction

Lisa 7. Fauci and Robert Dillon

Long Nonlinear Internal Waves

Karl R. Helfrich and W. Kendall Melville

Premelting Dynamics

7.S. Wettlaufer and M. Grae Worster

Large-Eddy Simulation of Turbulent Combustion

Heinz Pitsch 453

Computational Prediction of Flow-Generated Sound

Meng Wang, Fonathan B. Freund, and Sanjiva K. Lele 483

\section{INDEXES}

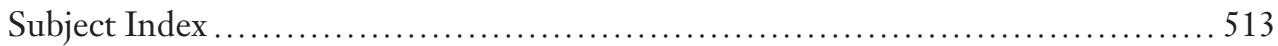

Cumulative Index of Contributing Authors, Volumes 1-38 ...................... 529

Cumulative Index of Chapter Titles, Volumes 1-38 f.......................... 536

\section{ERRATA}

An online log of corrections to Annual Review of Fluid Mechanics chapters may be found at http://fluid.annualreviews.org/errata.shtml 